\title{
Theory and Experiment in the Science on Human Motor Behavior
}

\author{
Wacław Petryński \\ Katowice School of Economics, Poland, Europe
}

Submission: November 02, 2018; Published: November 20, 2018

*Corresponding author: Wacław Petryński, Katowice School of Economics, 3 Harcerzy Września St. Katowice, Poland, Europe.

Abstract

The author presents and substantiates the opinion that in contemporary science exists a clear bias towards experimental researches, which do not entail a theory creation. On the other hand, just the theories, and not "new, original experimental data" make the "main body" of science. Modern technological devices make the collecting of such data easy, and simple statistical processing endows them with a "scientificity", often only apparent. Especially science on human motor behavior, which is of systemic nature, needs more interpretations and cannot be created by direct connections with the easily available results of experiments. Hence, the necessity of building strong "theoretical leg" in this discipline of science becomes more and more evident.

Keywords: Motor Science; Experimental Research; Theoretical Considerations

\section{Introduction}

\section{The Experimental Bias}

Let us start from the quotation from N.A. Bernstein of 1947: "The overflowing stream of new information in all the branches of natural science and, directly to its growth, the increasing differentiation of scientific and scientific-practical professions, create an increasing danger of turning their representatives into narrow specialists lacking any general horizon, blind to anything except the narrow path that they have chosen in life... it emasculates creative thinking, impoverishes their work with respect to fresh ideas and wide perspectives. Jonathan Swift, also about 200 years ago, predicted the emergence of such "Gelehrters" with blinkers on their eyes, blind, confused cranks; Swift sharply ridiculed them in his description of the Academy of Sciences on the Island of Lagado [1]".

In 1963 Bernard K. Forscher of Mayo Clinic, Rochester, Minnesota, published the paper entitled "Chaos in the Brickyard" [2]. It is easily available in Internet; hence I will not describe it in detail. Its "take home message" was that we observe the excessive bias towards experimental research while compared with theoretical works. Such a phenomenon slows down the real progress in science yet does not impair the feeling that producers of "new, original, experimental data" are "genuine" scientists. Symptomatically enough, the paper has been written more than half a century ago...

Guy Sorman interviewed Karl R. Popper, who stated: "universities, completely foolishly, have fragmented the knowledge into different, specialized branches; each of them, without any necessity, has been closed into its own ritual and terminology [3]".

Richard Schmidt and Timothy Lee, while commenting the achievements of Edwin A. Fleischman, wrote: "Fleishman's work leaves a legacy for future efforts on solving problems of prediction" [4]. What seems worth emphasizing: not "for solving problems", but "for future efforts on solving problems".

While comparing with these quotations, the following statement by Gerd Gigerenzer sounds rather ominously: "Some years ago I spent a day and a night in a magnificent library reading through issues of the "Journal of Experimental Psychology" from the 1920s and 1930s... What depressed me was that nearly all of this meticulous work has been forgotten. Most of it involved collecting data without substantive theory. Data without theory is like a baby without a parent: Its life expectancy is low. Are these the kind of babies we want to produce?" [5].

The "limited applicability" (it is for sure understatement) of rough or merely slightly statistically processed "new, original, experimental data" may originate in the phenomenon which Peter Medawar described with the words: "theory destroys facts" [6]. Moreover, only the theories make the science, and not the facts themselves. They may only serve as shapeless ashes, fertilizing the ground on which the theories grow.

However, the "intellectual environment" of the contemporary science is being characterized by two important factors: 
I. Easiness of data collecting, especially while using modern technological devices; then quotation of "learned" references and simple statistical processing endows the whole with some "scientificity".

II. Naïve belief that the quantity of data will "by itself" transform into science quality.

As the "intellectual daughter" of the latter might be regarded the "big data" technique. Cathy O’Neil has shown how dangerous or even disastrous might be thoughtless application of simplified-or even primitive, while compared with the complexity of reality-mathematical algorithms in the regions, where they are hardly useful or not applicable at all. She has even coined the ominously sounding term "weapon of math destruction" [7]. However, the mathematical equations work "by themselves"; hence, they release scientist from thinking. In addition, already in $18^{\text {th }}$ century Joshua Reynolds remarked. "There is no expedient to which a man will not resort to avoid the real labor of thinking".

This is why Jack Cohen and Ian Stewart argue that "At least 999 out of a thousand scientific papers are about complex details, but the one that we treasure and for which we award a Nobel Prize is the one that reveals a new simplicity" [8]. Still further went Paul Feyerabend, who argued that the society should be protected against science-apparently dignified, with nearly liturgical rituals, but in fact often worthless [9].

To sum up, one might state that the experimental results belong to reality, whereas science resides in the sphere of abstraction. There is no one-to-one relation between them. The gap between worlds of things, phenomena and processes on the one side, and words, statements and theories on the other, has to be bridged by reasoning and concluding, which by no means is clear and unambiguous. Nevertheless, it makes one and only way to science creation. Especially in disciplines, which nearly completely rely on reasoning and concluding, and to very limited extent on experimental data. Like, e.g., the science on human motor behavior.

\section{Typical Experimental Paper}

Let us take as an example a properly elaborated, precisely written, peer-reviewed, solid experimental paper. In 2018 Satoshi Unenaka, Sachi Ikudome, Shiro Mori and Hiroki Nakamoto published in "Frontiers in Psychology" the article entitled "Concurrent Imitative Movement During Action Observation Facilitates Accuracy of Outcome Prediction in Less Skilled Performers" [10]. It bases on results of researches into outcome prediction in two basketball players groups: skilled and less-skilled one. In abstract, they wrote: "The results showed that skilled group had degraded accuracy of outcome prediction in the self-motion condition compared to the observation condition. In contrast, accuracy in the less-skilled group was facilitated in the imitative-motion condition compared to the observation condition".
In fact, the authors presented the results of their experiments, supported by observations of other scientists (references). They associate, in some places of the paper, their results with the different theoretical findings of other scientists and have processed their results statistically. However, the statistics may make an image of reality sharper, indeed, but it is not able to explain "by itself", what namely is being presented on the image. In this respect, instructively sounds the following, slightly malicious, reflection of unknown author. "Statistical Analysis: Mysterious, sometimes bizarre, manipulations performed upon the collected data of an experiment in order to obscure the fact that the results have no generalizable meaning for humanity. Commonly, computers are used, lending an additional aura of unreality to the proceedings".

More detailed, and very instructively, the potentialities and limitations of statistics-and even some "dictatorship" of this discipline in modern science - have been described by Garland 0. Ashley [11]. He argued, "The statistical method has become used in altogether too many inappropriate and wholly inapplicable places in our professional life."

Hence, statistics is a discipline of science for statisticians, but only one of many tools for non-statisticians. It does not build a science "by itself". Here inevitable is an interpretation (by definition - subjective) and creation of a hypothesis. Unfortunately, Unenaka and his colleagues do not invent any coherent, conceptual rationale for their findings. Let us try to invent a specific rationale. To deserve the noble title "scientific", it has to be prone to critics and modifications.

\section{A Specific Rationale for Experimental Paper}

At first, let us categorize the "self-motion" as a motor operation controlled with the feedforward mode, and the "imitative-motion"-as a motor operation controlled with the feedback mode. The latter is by far more time-consuming and "intellectually expensive" [12]. However-not without reason-the feedback control mode is being regarded as one of the greatest achievements of evolution. Because it enables learning and perfecting the operations (also motor ones) under consideration. Nevertheless, the final aim of the feedback control mode is... elimination of the feedback loop. One might say that its mission is in fact suicidal. Hence, a skilled performer uses swifter and "intellectually cheaper" feedforward control mode. S/he does not need any extrinsic cue, and-to protect the "intellectual cheapness"-s/he blocks and rejects such cues.

By the way: Already in 18th century historian, Edward Gibbon remarked (very aptly) "the power of instruction is seldom of much efficacy, except in those happy dispositions where it is almost superfluous [13]".

While analyzing control modes of a motor operation, one might build a specific "control space". On its one border, we have the "hit-or-miss" method, typical for novices. It relies fully on feedback control; hence, it uses the extrinsic cues. Therefore, it 
is fully opened to learning process. On the other border of such a space, we have routine, which relies fully on feedforward control mode and ignores any extrinsic cue. Consequently, it is tightly closed to learning process.

In this respect, telling might be such a comparison. My driver's license is by far older than, e.g., that of Lewis Hamilton. However, he is no doubt much better driver than I am. Because I have attained some level of experience long ago and it is enough for me. It has already transformed, to great extent, into routine. I have only to learn, what mean the warning lights and indicators on the dashboard of my car, which did not exist in 1960s, when I have got my driver's license-long before Hamilton was born. However, to protect his title of champion, Hamilton has to apply incessantly the TTL-i.e., "testing the limits"-technique. He has to be open to incessant improvement of his driver's competence. In other words, while driving a car I can use the "intellectually cheap" feedforward control, whereas Hamilton is forced to apply the "intellectually expensive" feedback control mode.

The other problem is that the "imitative-motion", as by Unenaka and his colleagues, needs visual information processing, whereas the technique of free shot in basketball bases on contact stimuli (player's hand - ball), which cannot be observed from outside. However, a detailed analysis of this problem would need another theoretical paper. To great extent, it has been described in [12].

One more remark. Richard Schmidt wrote: "Since laws are the product of human creativity, different laws can be formulated by two different individuals who are examining the same observations. Laws do not automatically spring forth from the facts [14]".

Thus, "new, original, empirical data" evoke no doubts, whereas the theory is always ambiguous. Nevertheless, the Science (with great "S") consists of theories.

Symptomatic are the following statements of Uneneka et al., "In contrast, although learners accumulate knowledge about kinematic-outcome associations during perceptual training via perceptual experience, several recent studies have indicated the importance of motor experience for enhancing prediction abilities of athletes... Furthermore, recent evidence suggests that perceptual and motor experience develop different prediction mechanisms namely visual- and motorbased prediction, respectively. Motor experience more greatly improves prediction abilities based on kinematic cues than does perceptual experience such as observation of other's action".

Such a relation between visual and haptic aspects of a motor operation is coherent with the system-theoretical perspective of motor control in humans $(1 ; 12 ; 15 ; 16 ; 17)$. Accordingly, such aspects are not separated from each other, but they form a single, coherent-yet not homogenous-system. In other words, it is possible to invent a system-theoretical, scientific model which will account for such phenomena. Already in 1852, William B. Carpenter postulated close connection between mental and motor aspects of movements in living beings, sometimes even independent of current physical stimuli [18]. This phenomenon makes a basis for mind-to-muscle and muscle-to-mind techniques [19].

The reductionist analysis of such an aspect cannot explain the mechanism of human motor behavior. Because it "kills" probably the most elusive - and powerful as well - product of a system: the unpredictable, qualitatively new, emergent system effect. While seen from system-theoretical perspective, the science on human motor behavior consists mainly of system effects. This is why in this discipline mathematics seems to be hardly applicable.

\section{Conclusion}

The presented paper may be regarded as a comment to only several, arbitrarily chosen aspects of the typical, proper, solid experimental work by Unenaka and his colleagues. In conclusion, the authors of this paper wrote: "Further studies are needed to clarify the mechanism of enhancement in prediction through concurrent imitation because it is unclear from the results whether the less-skilled participants were actually using a type of motor-based simulation process".

Instead of a long exegetical analysis of this statement, let us remember the following anecdote about Albert Einstein: "During his stay in Zurich, the woman doctor, Paulette Brubacher, asked the whereabouts of his [Einstein's] laboratory. With a smile, he took a fountain pen out of his breast pocket and said: "here" [20]".

It seems more and more evident that in the science on human motor behavior we need like an oxygen the Einstein's fountain pen rather, and not new, original, experimental data.

Last (but not least) remark. Contemporary science is not a noble searching for objective truth, but simply business. Here applies the rule "publish or perish". However, to publish a paper, an author has to pay a publication fee. As a result, nowadays the "scientific strays" - like, e.g., the young assistant examiner, III level, in the Federal Office for Intellectual Property in Bern, Switzerland, named Albert Einstein -with no financial support from any institution, have no chances to make their ideas known to wide auditory. No matter, how valuable such ideas might be.

\section{References}

1. Bernstein NA (1996) On Dexterity and Its Development (in:) ML Latash, MT Turvey (Eds.), Dexterity and Its Development. Lawrence Erlbaum Associates, Mahwah, NJ, USA 26(1): 56-62.

2. Forscher BK (1963) Chaos in the Brickyard. Science 142(3590): 339.

3. Sorman G (1993) Prawdziwi myśliciele naszych czasów. Warsaw Czytelnik Poland, Europe.

4. Schmidt RA, Lee TD (2011) Motor Control and Learning. A Behavioral Emphasis. $5^{\text {th }}$ Edn. Champaign, IL: Human Kinetics, USA.

5. Gigerenzer G (2009) Surrogates for Theory. APS Observer 22(2): $21-$ 23.

6. Stewart I (2002) Does God Play Dice? The New Mathematics of Chaos. Second Edition Carlton Blackwell Publishing Australia. 
7. ONeil C (2016) Weapons of Math Destruction. How Big Data Increases Inequality and Threatens Democracy New York, Crown, USA.

8. Cohen J, Stewart I (2000) Collapse of Chaos Discovering Simplicity in a Complex World. London: Penguin Books, GB.

9. Feyerabend P (1975) How to Defend Society Against Science. (In:) ED Klemke, R Hollinger, DW Rudge, A. David Kline (Edn) Introductory Readings in the Philosophy of Science - $3^{\text {rd }}$ Edition 1998: 54-65.

10. Unenaka S, Ikudome S, Mori S, Nakamoto H (2018) Concurrent Imitative Movement During Action Observation Facilitates Accuracy of Outcome Prediction in Less Skilled Performers. Frontiers in Psychology 9: 1262

11. Ashley GO (1964) A Declaration of Independence from the Statistical Method. Air University Review 83.

12. Petryński W (2016) Motor Control in Humans. A System-Theoretical Approach. Hauppauge NY, Nova Science Publishers, USA.

13. Gibbon E (1995) The Decline and Fall of the Roman Empire. Hammondsworth, Middlesex Penguin Books, GB.

14. Schmidt RA (1988) Motor control and learning. A behavioral emphasis Second Edition. Champaign, IL: Human Kinetics Publishers Inc USA.
15. Bernstein NA (1947) O postroyenii dvizheniy. Moscow, Medgiz, Soviet Union.

16. Bernstein NA (1991) O lovkosti i yeyo razvitii. Moscow, Fizkultura sport, Russia.

17. Petryński W (2018) Formation of the Sensorimotor Operation Pattern from a System-Theoretical Perspective. International Journal of Physical Education, Fitness and Sports 7(2): 30-42.

18. Carpenter WB (1852) On the influence of suggestion in modifying and directing muscular movement, independently of volition. London: Royal Institution of Great Britain 12: 147-153.

19. Schmidt RA, Wrisberg CA (2008) Motor learning and performance: A situation-based learning approach. Champaign Human Kinetics USA.

20.Seelig C (1956) Albert Einstein: A Documentary Biography. Framingham MA Staples Press USA.

\section{Your next submission with Juniper Publishers} will reach you the below assets

- Quality Editorial service

- Swift Peer Review

- Reprints availability

- E-prints Service

- Manuscript Podcast for convenient understanding

- Global attainment for your research

- Manuscript accessibility in different formats

( Pdf, E-pub, Full Text, Audio)

- Unceasing customer service

Track the below URL for one-step submission

https://juniperpublishers.com/online-submission.php 